\title{
Liberdade e vontade de potência na filosofia de Nietzsche
}

\author{
Gustavo Arantes Camargo*
}

Resumo: O presente trabalho se propõe a pensar a questão da liberdade na filosofia de Nietzsche. Seria possível pensar a liberdade a partir da crítica radical ao livre-arbítrio e à moral feita pelo filósofo? Para isto, partiremos da caracterização da vontade de potência, entendida como expressão imediata de força e sempre em direção ao crescimento, para depois pensá-la em relação às ações humanas, entendendo que essas obedecem à mesma lógica. Por fim, a questão da liberdade será entendida enquanto proposta de fortalecimento e engrandecimento de si a partir de sua própria vontade e não de algum valor moral ou regra social.

Palavras-chave: Nietzsche, liberdade, vontade de potência.

* Universidade Federal do Rio de Janeiro, Rio de Janeiro, Rio de Janeiro, Brasil.

ORCID https://orcid.org/0000-0002-9066-2918

Correio eletrônico: gustavonhani@gmail.com 
Camargo, G. A.

\section{Introdução}

Conhecido por ser o filósofo cuja crítica fez por eliminar o papel da moral cristã como condutora de uma "boa sociedade", moral esta pregadora da ideia de que, caso todos ajam conforme a ideia de bem, a sociedade e a vida estariam a salvo em um reino de paz, Nietzsche segue muitas vezes mal interpretado ao ser pensado como defensor de uma filosofia apenas destrutiva e incapaz de propor algo afirmativo. Em sua filosofia, não apenas ataca a moral em seus fundamentos, deixando pouca esperança de que um agir moral possa ter um efeito benéfico sobre o mundo, como ainda, a partir do conceito de vontade de potência, instaura uma interpretação amoral e não racionalista da vida e da existência. Juntamente com a moral, Nietzsche destrói os conceitos que a sustentam, como, por exemplo, a ideia de um sujeito livre, dotado de uma faculdade que seria a vontade e que poderia ou não agir de acordo com sua autodeterminação.

No entanto, a filosofia da vontade de potência não nos conduz a um caos indeterminado, de onde nada se poderia esperar. Se é certo que "é preciso ter ainda um caos dentro de si, para dar à luz uma estrela dançante" (ZA/ZA, "Prólogo", 5, KSA 4.19) não é menos certo de que se trata também de "Dominar o caos que se é: constranger seu caos a tomar forma; a tornar-se necessidade na forma: a tornarse lógico, simples, inequívoco, matemático, a tornar-se lei -: esta é a grande ambição". (Nachlass/FP, 1888, 14[61], KSA 13.247) ${ }^{2}$

Este artigo tem o objetivo de pensar como Nietzsche resolve o impasse gerado pela destruição das categorias identitárias e universalistas que sustentam a metafísica da liberdade da ação,

1 Nietzsche, F. Assim falou Zaratustra. Tradução de Mário da Silva. Rio de Janeiro: Civilização brasileira, 2003. A partir de agora indicado como MS.

2 Nos casos em que a bibliografia citada se encontrava em língua estrangeira, em geral língua francesa, as traduções foram feitas por mim.

116 | Cad. Nietzsche, Guarulhos/Porto Seguro, v.42, n.3, p. 115-146, setembro/dezembro, 2021. 
que, em última instância, é o que legitima a cobrança moral ${ }^{3}$, sem cair em um total descontrole e em uma consequente incapacidade de construção de qualquer tipo de filosofia para além do niilismo.

\section{Caracterização da vontade de potência}

Em uma passagem de "Assim falou Zaratustra", fica claro que a crítica à moral traz consigo a ideia de vida como vontade de potência. "Mas, para que compreendais minhas palavras do bem e do mal, quero acrescentar, ainda, minha palavra sobre a vida e o modo de ser de todo o vivente" (ZA/ZA II, "Do superar a si mesmo", KSA 4.147. Tradução de MS). No mesmo discurso completa: "Onde encontrei vida, encontrei vontade de potência" (ZA/ZA II, "Do superar a si mesmo", KSA 4.147. Tradução de MS) ${ }^{4}$. Para Nietzsche, não se pode compreender a moral sem se levar em conta a vida e vida é crescimento, é expressão imediata de potência. "Uma criatura viva quer, antes de tudo, dar vazão a sua força - a própria vida é vontade de potência-" (JGB/BM 13, KSA 5.27) ${ }^{5}$

No aforismo número 36 de "Além do bem e do mal" (JGB/BM 36, KSA 5.54, tradução de PCS), Nietzsche expõe com clareza este conceito. Buscando entender a vida em uma perspectiva imanente, qual seria a melhor forma de abordá-la? Por onde deve o filósofo, crítico das categorias abstratas e das pretensões do entendimento puramente racionais, começar sua interpretação?

3 Como podemos ver em "Crepúsculo dos ídolos": “Os homens foram considerados 'livres' para poderem ser julgados, ser punidos - ser culpados: em consequência, toda ação teve de ser considerada como querida, e a origem de toda ação localizada na consciência". (GD/CI, "Os quatro grandes erros", 7, KSA 6.95. Tradução de Paulo Cezar de Souza)

4 Tradução modificada. Nos casos em que foi utilizada tradução em português, a única modificação realizada aconteceu nos casos onde substituí o termo "vontade de poder" por "vontade de potência", por uma questão de unificação do conceito no artigo. Neste caso, todas as ocorrências estão assinaladas.

5 NIETZSCHE, F. W. Além do bem e do mal. São Paulo: Companhia das letras, 1992. Tradução de Paulo César de Souza. A partir de agora indicado como PCS. Tradução modificada. 
Camargo, G. A.

Supondo que nada seja 'dado' como real, exceto nosso mundo de desejos e paixões, e que não possamos descer ou subir a nenhuma outra 'realidade', exceto à realidade de nossos impulsos - pois pensar é apenas a relação destes impulsos entre si -: não é lícito fazer a tentativa e colocar a questão de se isso que é dado não bastaria para compreender, a partir do que lhe é igual, também o chamado mundo mecânico (ou 'material')? (JGB/BM, 36, KSA 5.54, tradução de PCS)

Nietzsche apresenta sua hipótese tendo os desejos e as paixões ${ }^{6}$ como ponto de partida. Tais afetos são antes sentidos pelo corpo do que pensados pela consciência. Nietzsche criticou arduamente a tentativa de pensar a vida a partir de categorias representacionais em nome de uma espécie de subsolo dos instintos e impulsos que constituiria até mesmo o próprio pensamento. ${ }^{7}$ Assim, é coerente que inicie sua teoria a partir dos desejos e das paixões, isto é, em última instância, do corpo. Se o próprio pensamento é a relação entre os impulsos, por que não começar por aí o pensamento sobre a vida, ao invés de se começar pela razão ou pela consciência? "Tomar por ponto de partida o corpo e fazê-lo um fio condutor, eis o essencial. $\mathrm{O}$ corpo é um fenômeno muito mais rico e que autoriza observações mais claras. A crença no corpo é mais bem estabelecida que a crença no espírito" (Nachlass/FP, 1885, 40 [15], KSA 11.635). Se o corpo é mais importante do que o pensamento consciente é porque o “pensamento é, com efeito, apenas uma instância derivada, descritível a partir do jogo dos instintos, das paixões e das necessidades que constituem o corpo". (Wotling, 1999, p. 65) As paixões e os desejos

6 Desejos e paixões (Bergierden und Leidenschaften) são termos usados por Nietzsche na caracterização da vontade de potência. Ambos os termos aparecem como impulsos naturais humanos, marcando forte oposição em relação ao campo racional já delimitado tradicionalmente pela metafísica. Desta forma, como demonstraremos, Nietzsche toma o corpo e sua dimensão não racional como ponto de partida e fio condutor para sua análise da vontade de potência.

7 A este respeito: "Depois de por muito tempo ler nas entrelinhas dos filósofos, disse a mim mesmo: a maior parte do pensamento consciente deve ser incluída entre as atividades instintivas, até mesmo o pensamento filosófico; [...] também 'estar consciente' não se opõe de algum modo decisivo ao que é instintivo". (JGB/BM, 3, KSA 5.17, tradução de PCS)

118 | Cad. Nietzsche, Guarulhos/Porto Seguro, v.42, n.3, p. 115-146, setembro/dezembro, 2021. 
são expressões da vontade de potência no tocante ao caso particular da vida humana. $\mathrm{O}$ corpo oferece uma perspectiva mais confiável do que a perspectiva do espírito e do intelecto. "Se o corpo considera tanto nossas forças mais imediatas como as mais distantes, por sua origem, tudo aquilo que o corpo diz - seu bem-estar e seu mal-estar - nos dá as melhores informações sobre nosso destino" (Klossowski, 2000, p. 44).

A vontade de potência possui duas características que a definem. A primeira é que a potência é algo que se expressa a cada instante em toda sua plenitude. Não é algo que está em vias de se expressar e que pode ou não ser expresso. Potência é expressão imediata de força. Não há o trabalho do negativo em Nietzsche, nem a separação entre potência e ato. Toda realidade é expressão imediata de potência, por isto, tira suas últimas consequências a cada instante. Este é o caráter inexorável da vontade de potência. Esta é sua tirania. Uma definição imanente do mundo. Criticando a interpretação científica que vê leis na natureza, Nietzsche diz que

bem poderia vir alguém que, com intenção e arte de interpretação opostas, soubesse ler na mesma natureza, tendo em vistas os mesmos fenômenos, precisamente a imposição tiranicamente impiedosa e inexorável de reivindicações de potência - um intérprete que lhes colocasse diante dos olhos o caráter não excepcional e peremptório de toda 'vontade de potência', em tal medida que quase toda palavra, inclusive a palavra 'tirania', por fim parecesse imprópria, ou uma metáfora debilitante e moderadora demasiado humana; e que, no entanto, terminasse por afirmar sobre este mundo o mesmo que vocês [físicos] afirmam, isto é, que ele tem um curso 'necessário' e 'calculável', mas não porque nele vigoram leis, e sim porque faltam absolutamente as leis, e cada potência tira, a cada instante, suas últimas consequências. ${ }^{8}$ (JGB/BM, 22, KSA 5.37, tradução de PCS )

A outra característica é que toda vontade se direciona para uma elevação de potência, não para a conservação. $\mathrm{O}$ “"querer-se-tornar-

8 Tradução modificada.

Cad. Nietzsche, Guarulhos/Porto Seguro, v.42, n.3, p. 115-146, setembro/dezembro, 2021. | 119 
Camargo, G. A.

mais-forte’ emanando de todo centro de força é a única realidade não a autoconservação, mas a apropriação, querer-se-tornar-mestre, querer-se-tornar-mais, querer-se-tornar-mais-forte" (Nachlass/FP, 1888, 14[81], KSA 13.261). Ver na natureza e na vida a expressão imediata e inexorável da potência que se direciona para o aumento de sua força significa aceitar o conceito de vontade de potência como capaz de bem interpretar a "realidade".

Desta forma, o mundo é visto como jogo de forças, porém, cada força atua sempre em busca de crescimento, daí a inexorabilidade de uma luta. É a esta característica de luta incessante por crescimento, inerente a toda força devido ao fato de só existir enquanto expressão imediata, que Nietzsche chama de vontade de potência.

Este vitorioso conceito de 'força', graças ao qual nossos físicos criaram Deus e o mundo, necessita ainda de um complemento: é preciso atribuirlhe uma dimensão interior que chamarei 'vontade de potência', quer dizer, apetite insaciável de demonstração de potência; ou do uso e do exercício de potência, sob forma de instinto criador, etc. (Nachlass/FP, 1885, 36 [31], KSA 11.563)

Ao aceitar a vontade como atuante nestes termos, tem-se que avançar ainda mais um passo. "Vontade', é claro, só pode atuar sobre 'vontade' - e não sobre 'matéria' (sobre 'nervos', por exemplo -): em suma, é preciso arriscar a hipótese de que em toda parte onde se reconhecem 'efeitos', vontade atua sobre vontade - e de que todo acontecer mecânico, na medida em que nele age uma força, é justamente força de vontade, efeito da vontade". (JGB/BM, 36, KSA 5.55, tradução de PCS) O que há são forças em relação e cada força pode ser mais bem definida enquanto vontade de potência, na medida em que existe apenas enquanto expressão imediata de potência e em direção ao crescimento. Esta é a inexorabilidade da imanência, a inocência do devir, o caráter amoral e, por isto, trágico 
da existência; sua afirmação é a afirmação incondicional e dionisíaca do mundo e da vida.

Nietzsche enfatizará, então, o caráter relacional de toda força, de forma que um "quantum de potência se define pelo efeito que produz ou ao qual resiste. [...] É essencialmente uma vontade de exercer a violência e de se defender da violência". (Naschlass/FP, 1888, 14 [79], KSA 13.258) A vontade de potência é aqui definida em sua relação necessária com outra vontade, ela é esta violência relacional a outra vontade. É uma luta na qual cada vontade expressa toda sua potência a cada instante, violentando e sendo violentada, dominando e obedecendo, afetando e sendo afetada. Assim, Nietzsche vê o mundo como correlação de forças em combate umas com as outras, não havendo nada que escape a esta característica. "Não restam ainda as 'coisas', mas quanta dinâmicos: cuja essência reside em sua relação com todos os outros quanta, em suas 'ações' sobre estes - a vontade de potência, não um ser, não um devir, mas um pathos é o fato mais elementar, de onde só poderá resultar em um devir, um 'agir sobre"' (Nachlass/FP, 1888, 14 [79], KSA 13.259). A ideia de pathos vem do afeto de comando inerente à vontade, o que existe é a expressão das forças em relação umas com as outras, afetando e sendo afetadas, em direção ao aumento de potência. Não se deve diferenciar conceitualmente de forma estrita os conceitos de força e de vontade em Nietzsche. Toda força atuante é definida como vontade, a vontade de potência sendo a característica de toda força, a qualidade que a define. "Que toda força motora é vontade de potência, que não existe fora dela alguma força física, dinâmica ou psíquica..." (Naschlass/FP, 1888, 14 [121], KSA 13.300)

A vontade de potência não existe como unidade, somente em sua multiplicidade. Se a vontade de potência é a qualidade inerente às forças em relação, ela só pode ser pensada como unidade a partir da ideia de organização. "Toda unidade só é unidade enquanto organização e conjunto: tal como uma comunidade humana é uma 
Camargo, G. A.

unidade, e não de outra forma: sendo então, o contrário de um anarquismo atomista; e então, uma formação de dominação, que significa o Um, mas não é um". (Nachlass/FP, 1885 - 1886, 2 [87] KSA 12.104) Em seu jogo de dominação, a vontade que subjuga outra torna-se mais forte com ela, redireciona a vontade subjugada e forma com esta uma união não estável e sempre conflituosa, uma espécie de organização unitária. "Se ponderamos, de início, que essas aglomerações de quanta de potência ininterruptamente aumentam e diminuem, então só se pode falar de unidades continuamente mutáveis, não, porém, da unidade" (Muller-Lauter, 1997, p. 75). Essas organizações de quanta de potência estão em perpétuo movimento de conflito onde a própria força subjugada permanece exercendo pressão e resistência de maneira que a configuração muda com frequência.

Desta forma, Nietzsche termina por "definir toda força atuante, inequivocamente, como vontade de potência"9 (JGB/BM, 36, KSA 5.55, tradução de PCS). Isto é, tanto o mundo orgânico quanto o inorgânico, na medida em que se reconhece a vontade como efetiva e este efetivar-se como se dando sobre outra vontade, são abarcados pela filosofia da vontade de potência. "O mundo visto de dentro, o mundo definido e designado conforme o seu 'caráter inteligível' seria justamente "vontade de potência', e nada mais -" (JGB/BM, 36, KSA 5.55, tradução de PCS) ${ }^{10}$.

A adoção do termo vontade não aparece sem ressalvas na filosofia de Nietzsche. Muito pelo contrário, Nietzsche não só usa de grande cautela ao falar da vontade de potência como chega, em certos momentos, até mesmo a negar a existência de uma vontade, devido à maneira pela qual este termo havia sido pensado até então. (Nachlass/FP, 1887, 9 [98], KSA 12.391) As reticências do filósofo se devem, em grande parte, às próprias limitações da linguagem. $\mathrm{O}$ que o descontenta é o fato de que os "filósofos costumam falar da

9 Tradução modificada.

10 Tradução modificada.

122 | Cad. Nietzsche, Guarulhos/Porto Seguro, v.42, n.3, p. 115-146, setembro/dezembro, 2021. 
vontade como se ela fosse a coisa mais conhecida do mundo" (JGB/ BM, 19, KSA 5.31, tradução de PCS).

A palavra vontade é uma palavra amplamente usada no vocabulário coloquial, mas isto não a torna de definição fácil. "Querer me parece, antes de tudo, algo complicado, algo que somente como palavra constitui uma unidade (...)" (JGB/BM, 19, KSA 5.32, tradução de PCS). Na tentativa de definir seu conceito de vontade, a primeira coisa que ressalta é a pluralidade de elementos constituintes daquilo que usualmente se chama pelo único nome de vontade. "Há reunido em todo ato de vontade uma pluralidade de sensações" (Nachlass/ FP, 1885, 38 [8], KSA 11.606); "digamos que em todo querer existe, primeiro, uma pluralidade de sensações (...)" (JGB/BM, 19, KSA 5.32 , tradução de PCS). Aquilo que se sente como vontade já traz consigo inúmeras sensações como o estado que se tinha antes de senti-la, o estado para o qual se passa ao senti-la, toda mudança que ocorre no corpo com a passagem, etc. Todo o organismo se modifica a cada nova vontade.

Portanto, assim como o sentir, aliás muitos tipos de sentir, deve ser tido como ingrediente do querer, do mesmo modo, e em segundo lugar, também o pensar: em todo ato da vontade há um pensamento que comanda; - e não se creia que é possível separar tal pensamento do 'querer', como se então ainda restasse vontade! Em terceiro lugar, a vontade não é apenas um complexo de sentir e pensar, mas sobretudo um afeto: aquele afeto do comando (JGB/BM, 19, KSA 5.32, tradução de PCS).

Mais do que uma simples sensação, a vontade é um complexo amalgama de estados onde o pensar também se faz presente, sendo indissociáveis a vontade e o pensamento que a acompanha. A estes, Nietzsche acrescenta ainda $o$ afeto, $o$ afeto de comando. A vontade participa de um jogo de mando e obediência, de afetar e ser afetado, que envolve inúmeras sensações e pensamentos.

Em outros pontos Nietzsche mantém sua busca tateante: "Tratase de definir corretamente a unidade que engloba o pensamento, a 
Camargo, G. A.

vontade, a sensação e todas as paixões". (Nachlass/FP, 1885, 40 [38], KSA 11.647) Ou ainda, criticando a compreensão racionalista do conhecimento, diz: "nós tentamos compreender o mundo graças à concepção inversa - como se nada agisse nem fosse real, senão pensar, sentir, querer..." (Nachlass/FP, 1888, 14 [152], KSA 13.335). Por fim, "a vontade de potência, não um ser, não um devir, mas um pathos é o fato mais elementar" (Nachlass/FP, 1888, 14 [79], KSA 13.259). O mundo como resultado da expressão de um pathos. Este pathos sendo algo próximo, no ser humano, do querer, sentir e pensar, isto é, dos impulsos, dos instintos, das paixões e dos afetos. Este caráter impulsivo inerente à vida é a vontade de potência, é o impulso da potência para se expressar a cada instante, tirando suas últimas consequências e, assim, crescendo em força.

Dentro deste contexto, não constitui objeção à tese da atuação da vontade de potência a citação do próprio Nietzsche em “Crepúsculo dos ídolos" onde explicitamente nega a atuação da vontade: "No início está o enorme e fatídico erro de que a vontade é algo que atua - de que vontade é uma faculdade... Hoje sabemos que é apenas uma palavra..." (GD/CI, A razão na filosofia, 5, KSA 6.77) ${ }^{11}$.

Esta citação é parte de um trecho maior onde o filósofo aponta os preconceitos implícitos na linguagem que produzem um ser fictício por detrás da ação, dissociando justamente o sujeito e sua ação, a vontade e seu efeito, a potência e sua expressão. Vimos: toda força se expressa a cada instante, a imanência da vontade de potência reside na inexorabilidade de sua atuação. Eis um trecho maior do mesmo texto:

A linguagem pertence, por sua origem, à época da mais rudimentar forma de psicologia: penetramos um âmbito de cru fetichismo, ao trazermos à consciência os pressupostos básicos da metafísica da linguagem, isto é, da razão. É isso que em toda parte vê agentes e atos: acredita na vontade

11 NIETZSCHE, F. Crepúsculo dos ídolos. São Paulo: Companhia das letras, 2006. Tradução de Paulo César de Souza. A partir de agora indicado como PCS.

124 | Cad. Nietzsche, Guarulhos/Porto Seguro, v.42, n.3, p. 115-146, setembro/dezembro, 2021. 
como causa; acredita no 'Eu', no Eu como ser, no Eu como substância, e projeta a crença no Eu-substância em todas as coisas - apenas então cria o conceito de 'coisa'... Em toda parte o ser é acrescentado pelo pensamento como causa, introduzido furtivamente; apenas da concepção de 'Eu' se segue, como derivado, o conceito de 'ser'... No início está o enorme e fatídico erro de que a vontade é algo que atua- de que vontade é uma faculdade... Hoje sabemos que é apenas uma palavra... (GD/CI, A razão na filosofia, 5, KSA 6.77, tradução de PCS).

O problema, como bem nos esclarece o trecho acima citado, é a interpretação da vontade como faculdade, como se o sujeito fosse dotado de uma faculdade livre que pudesse ou não se expressar. A vontade que Nietzsche critica, portanto, é a vontade entendida dentro deste contexto proporcionado pela metafísica da linguagem que pressupõe um "eu" autônomo, racional e livre para agir e que, portanto, pode ser culpabilizado pela sua existência, por sua forma de vida, por ser quem é. Votaremos a este ponto.

\section{Vontade de potência e o ser humano:}

Se, por vezes, a vontade de potência aparece como "o desejo fundamental" (Grundbegierde) (Nachlass/FP, 1885-1886, 1 [59], KSA 12.25), ou como a unidade de todos os desejos, na medida em que estes se especializam cada vez mais (Nachlass/FP, 1885-1886, 1 [30], KSA 12.17), é porque, como vimos, Nietzsche vê os desejos e paixões como expressões da vontade de potência. ${ }^{12}$ Se o filósofo assim procede é porque entende que "a vontade de potência é a forma primitiva do afeto, que todos os outros afetos são apenas seu desenvolvimento". (Nachlass/FP, 1888, 14 [121], KSA 13.300) Daí

12 Nas duas citações vemos novamente o desejo como expressão da vontade de potência. Na segunda citação lemos: "die Begehrungen spezialisiren sich immer mehr: ihre Einheit ist der Wille zur Macht”. Em tradução livre: "Os desejos especializam-se cada vez mais: sua unidade é a vontade de potência". 
Camargo, G. A.

pensar a psicologia "como morfologia e teoria da evolução da vontade de potência" ${ }^{13}$ (JGB/BM, 23, KSA 5.38, tradução de PCS).

Isto significa que a dinâmica dos afetos possui a mesma característica anteriormente descrita para caracterizar a vontade de potência, ou seja, define-se pela atuação conflitante de forças em busca de supremacia e fortalecimento. "A vida não é um meio para qualquer coisa: ela é expressão das formas de crescimento da potência" (Nachlass/FP, 1887, 9 [13], KSA 12.345). Jogo e luta de forças, é assim que Nietzsche interpreta a vida como expressão da vontade de potência. "A vida estaria por definir como uma forma durável de um processo de equilibração de forças ou de diferentes combatentes se desenvolvendo cada um por sua vez de forma desigual". (Nachlass/ FP, 1885, 36 [22], KSA 11.560) A luta é incessante e perpétua, contudo, mesmo quando uma força é vencida e submetida à outra, sua resistência ainda se faz sentir. Uma força que obedece não é aniquilada, é dominada por uma força tirânica maior, sua potência é dobrada em outra direção. "Na medida em que uma certa resistência existe ela mesma na obediência; a potência propriamente não é nunca abandonada. Da mesma forma o comando implica a concessão que a potência absoluta do adversário não seja vencida, assimilada, dissolvida. 'Obedecer' e "mandar' são as formas do torneio" (Nachlass/ FP, 1885, 36 [22], KSA 11.560).

A partir desta multiplicidade dos afetos, Nietzsche pode pensar o ser humano como uma "prodigiosa síntese de seres vivos e de intelectos" (Nachlass/FP, 1885, 37 [4], KSA 11.577). A luta de Nietzsche contra o primado da razão e da consciência em prol do corpo e dos afetos no entendimento da vida se deve ao fato de que os primeiros não são capazes de dar contas dos movimentos subterrâneos que tornam a vida possível. É à luta das forças por potência que Nietzsche chama de vida, sendo a consciência um desenvolvimento posterior desta. Não é possível captar todos os movimentos e todos

13 Tradução modificada

126 | Cad. Nietzsche, Guarulhos/Porto Seguro, v.42, n.3, p. 115-146, setembro/dezembro, 2021. 
os porquês que se desenvolvem no corpo a cada instante. Mas, são justamente esses movimentos os mais importantes, aí se travam as lutas das quais temos apenas a sensação dos resultados, ainda que a cada instante. Desta forma, o corpo é metaforicamente entendido como cooperação de seres microscópicos em direção à potência.

E mesmo esses seres vivos microscópicos que constituem nosso corpo (ou melhor, cuja cooperação não pode ser mais bem simbolizada do que por aquilo que chamamos de 'corpo'一) não são átomos espirituais, mas seres que crescem, lutam, aumentam ou perecem: de forma que seu número muda perpetuamente e que nossa vida, como toda vida, é, ao mesmo tempo, uma morte perpétua. Há, pois, no homem, tantas 'consciências' quantos seres (a cada instante de sua existência) que constituem seu corpo. (Nachlass/ FP, 1885, 37 [4], KSA 11.577)

Este conjunto a que chamamos corpo seria uma espécie de consciência superior, justamente por constituir-se em uma hierarquia de funções, em uma aristocracia, não apenas de células, tecidos, órgãos, mas de "seres vivos microscópicos" que atuam em diversas direções, somos uma pluralidade de consciências. "Guiados pelo fio condutor do corpo, como já disse, apreendemos que nossa vida só é possível graças ao jogo combinado de numerosas inteligências de valor desigual, ou seja, graças a uma perpétua mudança na obediência e no comando sob formas inumeráveis" (Nachlass/FP, 1885, 37 [4], KSA 11.578). O sujeito, ou aquilo que entendemos como tal, não constitui uma unidade, é antes uma pluralidade de manifestações da vontade de potência que lutam entre si. "A luta tem caráter geral: ocorre em todos os domínios da vida e, sobretudo envolve os vários elementos que constituem cada um deles. Deflagrando-se entre células, tecidos ou órgãos, entre pensamentos, sentimentos ou impulsos, implica sempre múltiplos adversários, uma pluralidade de beligerantes" (Marton, 2000, p.61). A vitória temporária de alguns força os outros à submissão, o que nos dá um caráter aparente de unidade. Essa luta incessante faz com que a cada momento uma 
Camargo, G. A.

força diferente se sobressaia. "Desse ponto de vista, a luta garante a permanência da mudança: nada é senão vir-a-ser, ela faz também com que se estabeleçam hierarquias -" (Marton, 2000, p.44).

O essencial é que em "todo querer a questão é simplesmente mandar e obedecer, sobre a base, como disse, de uma estrutura social de muitas "almas" (JGB/BM, 19, KSA 5.33, tradução de PCS). A palavra alma não deve indicar uma estrutura fundante ou transcendente do organismo. Nietzsche define anteriormente "“alma como estrutura social dos impulsos e dos afetos" (JGB/BM, 12, KSA 5.27, tradução de PCS). Ou seja, na questão do querer trata-se do mando e da obediência entre muitos conjuntos de muitos impulsos e afetos cada. Uma multiplicidade inalcançável à consciência e que costuma causar erros. "Um homem que quer - comanda algo dentro de si que obedece, ou que ele acredita que obedece" (JGB/BM, 19, KSA 5.32, tradução de PCS). Mas, tanto o mando como a obediência se dão no mesmo terreno, no caso, o corpo. Por isto, acredita-se que o ato de vontade seja um ato consciente e livre, sendo chamado de livre-arbítrio. Chama-se livre-arbítrio ao resultado do combate entre os impulsos e chama-se sujeito ao suposto executor consciente da ação. Mas a vontade não é uma faculdade cujo sujeito, portador desta faculdade, decidiria sobre sua realização ou não. Cada vontade tira suas últimas consequências a cada instante, quando a vontade é mais forte do que as resistências, a ação é natural, faz parte da vontade o seu exercício em ato. "Ao contrário do que supõe a 'teoria psicológica', o sujeito não é o executor da ação e sim o seu "efeito" (Marton, 2000, p.46). Erramos quando culpamos a vontade que manifesta toda sua força agindo, como se lhe fosse possível ter agido de forma diferente ou não ter agido. Erramos também ao interpretar a vontade fraca como virtuosa por se abster daquilo que ela não pode. Estes erros ocorrem a partir da pressuposição da existência de um "sujeito livre" que "decide conscientemente" o que fazer. "Através do sintético conceito de 'eu', toda uma cadeia de conclusões erradas e, em consequência, 
de falsas valorações da vontade mesma, veio a se agregar ao querer - de tal modo que o querente acredita, de boa fé, que o querer basta para agir" (JGB/BM, 19, KSA 5.33, tradução de PCS). Porém, como a vontade de potência atua em cada microrganismo, somos sempre tomados por diversas vontades diferentes que se encaminham em diversos sentidos diferentes. "O homem enquanto multiplicidade de 'vontade de potência': cada uma com uma multiplicidade de meios de expressão e de formas" (Nachlass/FP, 1885 - 1886, 1[58] KSA 12.25). A ação é apenas o resultado da luta entre as vontades de um corpo. O que vemos por fim é o resultado do combate e que, por isto, nos aparenta uma unidade. Ao nos identificarmos com a ação, acreditamos ser também os responsáveis por tais ações. É muito comum o recurso retórico aos motivos que impulsionariam ações, declarando-se que uma ação foi tomada devido a um determinado motivo. Mas esta própria luta dos motivos traduz apenas o jogo impulsivo subterrâneo do qual quase não se tem acesso e, caso o motivo exista, seria "algo para nós completamente invisível e inconsciente" (M/A, 129, KSA $3.119)^{14}$. O que se tem sempre é o conhecimento do resultado da luta dos motivos, mas "a luta mesma se acha oculta de mim, e igualmente a vitória, como vitória; pois venho a saber o que faço - mas não o motivo que propriamente venceu" (M/A, 129, KSA 3.119, tradução de PCS). O fato é que "continua existindo a antiquíssima ilusão de saber, saber com precisão em cada caso, como se produz a ação humana" (M/A, 116, KSA 3.108, tradução de PCS). E, por mais que o próprio Nietzsche se debruce com afinco sobre esta questão, concluirá que "o que se pode saber sobre uma ação não basta jamais para fazê-la, que a ponte do conhecimento ao ato não foi lançada nem uma vez até hoje? Os atos não são jamais aquilo que parecem ser" (M/A, 116, KSA 3.109, tradução de PCS). Por fim, tem-se que

14 NIETZSCHE, F. Aurora., Companhia das letras, 2004. São Paulo. Tradução de Paulo César de Souza. A parti de agora indicado como PCS. 
Camargo, G. A.

"todos os atos são essencialmente desconhecidos" (M/A, 116, KSA 3.109, tradução de PCS).

Dentro desta ótica, não há sujeito por trás da ação, a cada momento o "sujeito" muda, o sujeito é, na verdade, vir-a-ser, pois a cada momento altera-se a correlação de forças. "O conceito de 'individuo' é falso. Estes seres [microscópicos atuantes] não existem isoladamente: o centro de gravidade se desloca; a contínua produção de células, etc., causa uma mudança perpétua do número desses seres" (Nachlass/FP, 1885, 34 [123], KSA 11.462).

\section{Liberdade e racionalidade}

Após tudo o que foi dito, seria possível pensar a ideia de liberdade a partir da filosofia de Nietzsche? Em outras palavras, ao descartar que a vontade seja uma faculdade, ao abolir o livre-arbítrio, ao dar primazia aos impulsos e afetos em detrimento da razão, ao corpo em relação à consciência, como não entender o ser humano como um autômato?

É importante notar que, se Nietzsche descarta o livre-arbítrio, também o faz em relação ao seu oposto, o "cativo-arbítrio"15 (JGB/ BM, 21, KSA 5.35, tradução de PCS). Ou seja, a teoria da vontade de potência não implica em um ser autômato e sem capacidade de reação sobre si próprio. Assim como também não aceita a ideia de um sujeito livre, dotado da vontade como faculdade. Quando se critica a vontade livre ou o livre arbítrio, é comum que daí decorra a afirmação diametralmente oposta, isto é, se aquilo que fazemos não decorre de nossa livre deliberação, então fazemos de maneira involuntária, à força, contra nossa própria vontade. Nesta perspectiva, não teríamos nenhum controle sobre nossas ações. Ora, como agimos inúmeras vezes de bom grado e sem que nos sintamos constrangidos, preferimos

15 Em nota de tradução, Paulo César de Souza aponta que "cativo-arbítrio" traduz "unfreier Wille", literalmente "vontade não livre".

130 | Cad. Nietzsche, Guarulhos/Porto Seguro, v.42, n.3, p. 115-146, setembro/dezembro, 2021. 
acreditar no livre-arbítrio e descartar o cativo-arbítrio. Contudo, sabemos que Nietzsche julga os dualismos como formas superficiais e metafísicas de avaliação, falta a nuance do pensamento nesse tipo de análise. Como visto na seção anterior, quando obedecemos à nossa própria vontade ou nos identificamos com ela, isso não significa que obedeçamos a uma faculdade racional deliberativa livre. Para Nietzsche, o fato de o sujeito não ser o causador livre de suas ações não implica que seja um autômato. Concluímos, com isso, que há um espaço para se pensar a liberdade na filosofia de Nietzsche e nosso objetivo será a caracterização desta liberdade.

A liberdade em Nietzsche será pensada como uma espécie de organização interna das vontades realizada pelas próprias vontades. O filósofo entenderá que "o domínio da potência consiste, então, em uma combinatória de instintos" (Wotling, 1999, p.207) e não em um ato racional facultativo.

[...] mas querer combater a veemência de um impulso não está em nosso poder, nem a escolha do método, e tampouco o sucesso ou fracasso desse método. Em todo esse processo, claramente, nosso intelecto é antes o instrumento cego de um outro impulso, rival daquele que nos atormenta com sua impetuosidade [...] Enquanto 'nós' acreditamos nos queixar da impetuosidade de um impulso, é, no fundo, um impulso que se queixa de outro; isto é: a percepção do sofrimento com tal impetuosidade pressupõe que haja um outro impulso tão ou mais impetuosos, e que seja iminente uma luta, na qual nosso intelecto precisa tomar partido (M/A, 109, KSA 3.98, tradução de PCS).

$\mathrm{O}$ intelecto aparece sempre como um instrumento a serviço dos instintos, não como o instinto fundamental. O que essa passagem mostra é que, mesmo que a razão tivesse o poder de controlar a vontade, ela ainda assim estaria agindo em função de uma outra vontade anterior. A atuação da razão, qualquer que seja sua dimensão, já é uma atuação posta em movimento por instintos. $\mathrm{O}$ intelecto toma partido, mas a própria direção de sua ação é dada a partir do instinto 
Camargo, G. A.

do qual ele é função "Não há causas mentais absolutamente!” (GD/ CI, Os quatro grandes erros, 3, KSA 6.91, tradução de PCS).

Para Nietzsche, somente o medo de sucumbir às paixões pode levar a uma supervalorização da racionalidade. "Quando há necessidade de fazer da razão um tirano, como fez Sócrates, não deve ser pequeno o perigo de que uma outra coisa se faça de tirano. A racionalidade foi então percebida como salvadora, nem Sócrates nem seus 'doentes' estavam livres para serem ou não racionais isso era de riguer, era seu último recurso". (GD/CI, O problema de Sócrates, 10, KSA 6.72, tradução de PCS) Na filosofia de Nietzsche trata-se, então, de criar um ser capaz de lidar livremente com seus impulsos sem aprisioná-los pela racionalidade e pela moral, mas sem sucumbir a eles. É aí que reside precisamente a tragicidade e toda dificuldade da questão: a liberdade não é racional.

A ação é o resultado destas lutas e não a causa, este resultado se expressa em forma de hierarquia. Em um fragmento póstumo intitulado "Da hierarquia" (Nachlass/FP, 1885 - 1886, 2 [76], KSA 12.96), Nietzsche faz apontamentos para uma "psicologia da potência", sendo o primeiro: "A aristocracia no corpo, a multiplicidade de elementos dominantes (combate dos tecidos?" e o segundo, "A escravidão e a divisão do trabalho: o tipo superior, unicamente possível graças a redução constrangedora de um tipo inferior a uma só função".

Este trecho é capaz de esclarecer vários pontos a uma só vez. O estudo sobre as manifestações da potência é a psicologia, que deve, justamente, atentar para o caráter conflituoso inerente ao âmbito impulsivo. Este âmbito impulsivo, caracterizado pelo conflito incessante de forças umas sobre as outras por maior potência e supremacia adquire seu grau mais alto pela organização, muitas vezes tirânica, das forças em uma direção apenas. Contudo, esta canalização de todas as forças para uma mesma direção se dá como resultado temporário de um combate. A força tirânica impõe às demais sua direção, escraviza-as, formando uma aristocracia. O tipo superior 
decorre da escravização dos tipos inferiores à direção de sua força. $\mathrm{Ou}$ seja, mesmo não se tratando de um processo controlado pela razão, existe uma possibilidade de organização interna de nossas forças constitutivas de forma a direcioná-las para um aumento de potência. A questão da hierarquia interna das forças torna-se central para pensarmos a possibilidade da liberdade sem cairmos no moralismo do livre-arbítrio.

Uma vez definido o ser humano como "uma pluralidade de forças que se situam em uma hierarquia" (Nachlass/FP, 1885, 34 [123], KSA 11.461) de forma que há o comando e a obediência, mas não a aniquilação das forças em relação, passaremos para a questão da força ou fraqueza da vontade, ou melhor, para a organização das vontades de forma que se tornem cada vez mais fortes. As diretrizes básicas daquilo que estamos tentando entender como liberdade em Nietzsche podem ser inicialmente apresentadas por um belo e esclarecedor fragmento póstumo:

Fraqueza da vontade: esta é uma imagem que pode induzir a erro. Pois não existe vontade, e, por consequência, nem forte nem fraca. A multiplicidade e a desagregação dos impulsos, a falta de um sistema de coordenadas resulta em uma 'vontade fraca'; sua coordenação sob a predominância de um só impulso resulta na 'vontade forte'; - em um primeiro caso, é a oscilação contínua e a falta de centro de gravidade; no segundo, a precisão e a claridade da direção. (Nachlass/FP, 1888, 14 [219], KSA 13.394)

\section{Liberdade e vontade de potência}

Historicamente, a escolha de valores morais como critérios de julgamento da conduta humana foi a forma como a civilização ocidental tentou dar conta da vontade. Contudo, um dos grandes problemas em relação à moral é que esta, ao invés de ensinar o domínio do ser humano em relação a suas paixões e desejos, busca não só enfraquecê-los como extirpá-los de uma vez por todas ao proibi- 
Camargo, G. A.

los como moralmente indesejáveis. Contudo, "aniquilar as paixões e os desejos (Leidenschaften und Bergierden) apenas para evitar sua estupidez e as desagradáveis consequências de sua estupidez, isso nos parece, hoje, apenas uma forma aguda de estupidez" (GD/CI, Moral como antinatureza, 1, KSA 6.82, tradução de PCS). Se tais afetos podem trazer consigo consequências estúpidas e funestas, isto não significa que devam ser negados e enfraquecidos até que sumam. O tipo forte ou nobre aprenderá a dominar suas paixões e a usá-las a seu favor. Assim, Nietzsche fala de um "delírio dos moralistas que consiste em exigir, ao invés de se dominar as paixões, sua extirpação. Sua conclusão é sempre: somente o homem emasculado é um homem 'bom"' (Nachlass/FP, 1888, 14[163], KSA 13.347). A moral, ao negar a vontade, nega a própria vida, tudo isto devido ao fato de que as paixões acarretam, por vezes, consequências desagradáveis, logo, conclui o moralista, são más. Contrariamente às filosofias e religiões morais, Nietzsche conclui:

Aprecio o homem segundo o quantum de potência e abundância de sua vontade: não segundo a falência e extinção destas: considero uma filosofia que ensina a negação da vontade enquanto uma doutrina da degradação e da calúnia... (Nachlass/FP, 1887, 10[118], KSA 12.524)

No caminho inverso da moral que buscou sempre negar a vontade, Nietzsche almeja um tipo forte o suficiente para poder usar até mesmo suas paixões mais temíveis a seu próprio favor. Sua filosofia se dirige a um "crescimento da força para poder se servir das mais violentas potências naturais, os afetos..." (Nachlass/FP, 1887, 10[203], KSA 12.581).

Meu critério de medida: até onde um homem, um povo pode desacorrentar em si seus instintos mais reprováveis e os dobrar para sua saúde, sem que eles o levem a se perder: mas, ao contrário, que o leve à sua fecundidade, em atos e em obras (Nachlass/FP, 1885 - 1886, 1[5], KSA 12.11). 
Os afetos são as forças mais potentes da natureza, não estranha que tenham sido mantidos sob controle. Eles possuem uma força destrutiva para si ou para os demais, o perigo em lidar com eles é iminente. A moral os controla por medo, mas, com isto, elimina-se a principal força da vida. Para Nietzsche, as grandes personalidades sempre foram seres de vontade forte, ou melhor, como vimos acima, é a organização interna da vontade que impulsiona o ser humano a criar e produzir coisas belas e interessantes. A negação moral da vontade resulta em um animal dócil e domesticável. Por isso, Nietzsche entende a moral como antinatureza e diz que "atacar as paixões pela raiz significa atacar a vida pela raiz" (GD/CI, Moral como antinatureza, 1, KSA 6.83, tradução de PCS). Sua proposta é inequívoca:

Em resumo: dominar as paixões, não enfraquecê-las, nem extirpá-las!

Maior será a soberania do querer, mais ela saberá conceder liberdade às paixões.

A grandeza do "grande homem" reside na margem de liberdade de seus desejos e mais ainda na potência ainda maior com a qual saberá tomar a seu serviço estes monstros esplêndidos. (Nachlass/FP, 1887, 9[139], KSA 12.414)

Não é uma tarefa fácil, pois se trata da potência mais violenta da natureza. Nietzsche as chama de monstros esplendidos. A moral aparece como resultado da fraqueza em dominar nossos monstros esplêndidos. Mas, a questão da liberdade consiste, justamente, em conceder liberdade às paixões, inclusive às mais violentas $\mathrm{e}$ destrutivas e, aí inserido neste jogo de morte, dominá-las e usá-las para seu próprio benefício. Sua força deve ser usada para enriquecimento e embelezamento da vida. A decadência é a incapacidade de lidar com seus monstros esplêndidos e a consequente invenção de regras morais com o intuito de contê-los. Em um determinado momento, Nietzsche diz: "um espírito mestre de si sabe agir mesmo a respeito de 
Camargo, G. A.

seus cães selvagens" (Nachlass/FP, 1885, 38[20], KSA 11.617). Esta imagem dos cães selvagens para caracterizar a violência dos impulsos aponta não só para sua força, mas também para a comum crença na necessidade de ter que aprisioná-los. A filosofia de Nietzsche será a tentativa de lidar com os cães selvagens das paixões, esses monstros esplendidos, dominá-los e usá-los em seu próprio proveito, sem enfraquecê-los ou extirpá-los. Uma vez que "quase todas as paixões possuem má reputação por causa daqueles que não são fortes o suficiente para usá-las a seu favor" (Nachlass/FP, 1888, 14[157], KSA 13.341), caberá aprender a dominá-las, a espiritualizá-las.

Neste sentido, Nietzsche aponta seu tipo forte: "Mas para os espíritos mais fortes, a exigência que comanda é que sejam certamente homens de paixão, mas também o mestre de suas paixões, mesmo quando se trate de sua paixão pelo conhecimento" (Nachlass/FP, 1885, 38[20], KSA 11.617). É preciso autorizar o instinto a se manifestar, pois este é expressão de vida, de vontade de potência. "O instinto fala fortemente: lá onde este instinto relaxa [...], pode-se concluir com certeza sobre o esgotamento e a degenerescência" (Nachlass/FP, 1887, 9 [30], KSA 12.349). Contra as morais da fraqueza, Nietzsche brada: "Que se devolva aos homens a coragem para seus impulsos naturais" (Nachlass/FP, 1887, 9[121], KSA 12.406).

A dificuldade em dominar as paixões decorre não só de sua força inerente, mas também de seus antagonismos. Lembremos que vontade atua sobre vontade, há um conflito constante entre elas, a vitória de uma vontade específica é sempre temporária e instável, isto é, o domínio de si é antes um frágil equilíbrio em uma pluralidade de vontades beligerantes. Em seu entendimento sobre a liberdade, Nietzsche propõe o fortalecimento e o aprimoramento das paixões para que estas sejam capazes de lidar com as demais paixões. Não é um controle da razão consciente sobre o desejo impulsivo, mas uma luta entre paixões antagônicas, onde a paixão mais forte dominará. $\mathrm{O}$ antagonismo impulsivo no interior de um mesmo corpo não é um 
motivo contra este, ao contrário, será destas grandes lutas antagônicas que sairá uma grande paixão e uma grande obra.

O essencial é que os homens verdadeiramente grandes tenham talvez também grandes virtudes, mas, justamente, ainda mais as antíteses destas. Acredito que é na presença destas contradições, e do sentimento destas contradições que nasce precisamente o grande homem, o arco dotado da mais alta tensão (Nachlass/FP, 1885, 35[18], KSA 11.515).

O engrandecimento de si é entendido como aprimoramento dos afetos e decorre do domínio exercido por uma grande paixão sobre as demais, chegando ao cúmulo de poder conceder liberdade às paixões mais violentas sem que estas ponham tudo a perder. Ao contrário, como já foi dito, é preciso saber usar até mesmo estas paixões funestas a seu próprio favor. Por isto, um dos ingredientes principais neste caminho é a coragem. "Ter espírito não é suficiente: é preciso ainda o assumir e isto exige muita coragem" (Nachlass/FP, 1884 - 1885, 31[52], KSA 11.386). Se a condição para uma vida liberta de toda moral é, não só a riqueza e força das paixões, mas também a riqueza e forças das paixões antagônicas, entende-se o papel da coragem neste processo. É mais fácil, com certeza, adequar-se aos valores estabelecidos e, desta forma, ser aceito socialmente do que se tornar si mesmo, senhor de seus desejos e paixões. É comum negar até a si mesmo as paixões mais inconfessáveis, $o$ medo de não ser aceito ou a elas sucumbir não é despropositado. O caminho dionisíaco e trágico aqui proposto, ao contrário do moral, não foge diante aos riscos, mas aceita-os como necessários.

Um dos grandes problemas neste caso é que aquele que busca seguir seu próprio caminho não encontra ninguém que possa ajudálo nos momentos de dificuldade, trata-se sempre de um caminho solitário (Nachlass/FP, 1885-1886, 2[186], KSA 12.159). Com efeito, a decisão de estabelecer por si mesmo seus próprios valores e a busca pelo domínio de suas paixões, não para proibi-las, mas para 
Camargo, G. A.

delas dispor, tem como consequência o destacamento em relação à moral estabelecida e amplamente seguida por aqueles a quem Nietzsche chamará de rebanho e a consequente autonomia e solidão daqueles a quem Nietzsche chamará de senhores. Ter vontades fortes, antagônicas, selvagens, monstruosas e usá-las a seu favor parece uma tarefa impossível. Mas é neste sentido que Nietzsche diz que "apenas o excesso de força é prova de força" (GD/CI, Prólogo, KSA 6.57, tradução de PCS). Esta é a nobreza de espírito, o sim dionisíaco à vida com toda sua intensidade. Se existe liberdade na filosofia de Nietzsche, trata-se de uma liberdade dionisíaca e trágica.

É preciso saber se se é capaz de querer algo e de, para tanto, superar as demais volições que se interponham à realização de tal vontade superior. "O homem, tornado mestre de suas forças naturais, mestre de sua selvageria e de sua fúria própria: os desejos aprendem a obedecer, a ser úteis" (Nachlass/FP, 1887-1888, 11[111], KSA 13.52). A grande paixão, quando dominada e orquestrada em uma direção ganha em estilo, torna-se espiritualizada. (Espiritualizada em um sentido amoral, isto é, trabalhada, aprimorada, aperfeiçoada e tornada bela, de forma alguma transposta a um patamar espiritual separado de um outro patamar qualquer). É possível se cultivar os impulsos como um jardineiro (M/A, 560, KSA 3.326, tradução de PCS). O grande estilo surge do sucesso do trabalho sobre uma paixão forte.

Dominar o caos que se é: constranger seu caos a tomar forma; a tornar-se necessidade na forma: a tornar-se lógico, simples, inequívoco, matemático, a tornar-se lei -: esta é a grande ambição (Nachlass/FP, 1888, 14[61], KSA 13.247).

Caos de vontade, assim Nietzsche define o ser humano capaz de vontades fortes, o ser não-moral. Este caos de vontade, é claro, é perigoso e não implica por si só em nada de grandioso. Mas é deste solo caótico de impulsos, paixões e desejos arrebatadores, somente 
deste solo selvagem e brutal ainda presente neste bicho hoje chamado humano, é somente daí que algo pode ser produzido com a grandeza e a beleza necessárias para fazer jus àquilo que se chama vida. "Eu vos digo: é preciso ter ainda um caos dentro de si, para poder das à luz uma estrela dançante. Eu vos digo: há ainda caos dentro de vós" (ZA/ZA, O prólogo de Zaratustra, 5, KSA 4.19. Tradução de MS). Vida como vontade de potência, vontade de potência como característica da vida de buscar sempre por mais potência, a vida se enaltece diante da grande paixão, do grande desejo tornado senhor de si e dos demais. A tirania da vontade em relação às demais vontades, em direção ao grande estilo. Talvez aqui a ética encontre a estética. O belo como produto de uma vida plena, vida plena como vontade plena, beleza da vontade como beleza da vida.

Uma das grandes dificuldades deste processo é o risco de sucumbir às paixões, é o risco da anarquia interior, do desregramento e da falta de direção. Conceder liberdade aos instintos não significa realizar quaisquer desejos a qualquer momento, não significa ceder a qualquer mínima volição simplesmente porque a moral não mais os rege. Ao contrário, é importante "não confundir a libertinagem, o princípio do 'deixar acontecer' com a vontade de potência (que é o princípio contrário)" (Nachlass/FP, 1888, 15[67], KSA 13.451). Nada mais antagônico à liberdade da vontade de potência do que o descontrole sobre os impulsos. Nietzsche chama a libertinagem do espírito e a vagabundagem de metamorfose do niilismo (Nachlass/FP, 1888, 13[1], KSA 13.213). A liberdade concedida aos impulsos em relação à moral pode acarretar a perda de si mesmo e a incapacidade de fortalecimento de uma grande vontade, uma vez que os cães selvagens podem vencer a luta e se interpor ao domínio de si, mas isto não implica na necessidade de um retorno à moral. "Os meios radicais são indispensáveis somente para os degenerados; a fraqueza da vontade ou, mais exatamente, a incapacidade de não reagir a um estímulo, é ela mesma apenas outra forma de degenerescência" 
Camargo, G. A.

(GD/CI, Moral como antinatureza, 2, KSA 6.83, tradução de PCS). A anarquia dos instintos, a dissociação e falta de organização entre as vontades, a carência de uma força mestra e comandante, isto tudo é sintoma de decadência, ou degenerescência, como Nietzsche gosta de falar nesse caso, apontando para o caráter fisiológico de sua psicologia. A necessidade da moral é um sintoma da incapacidade de domínio de si, sendo assim, "não podemos mais, hoje em dia, conceber a degenerescência moral independentemente da degenerescência fisiológica" (Nachlass/FP, 1888, 14[113], KSA 13.290). Mais adiante no mesmo fragmento, Nietzsche define degenerescência fisiológica como algumas incapacidades, como, por exemplo: "a fraqueza da vontade, a insegurança e mesmo a pluralidade de 'personalidades', a impotência a suspender uma reação à primeira solicitação que se apresenta e a se 'dominar', a falta de liberdade diante da menor sugestão de uma vontade estrangeira" (Nachlass/FP, 1888, 14[113], KSA 13.290). O que Nietzsche chama de degenerescência e doença é a incapacidade de não reagir a um estímulo volitivo. "Toda nãoespiritualidade, toda vulgaridade se baseia na incapacidade de resistir a um estímulo - tem-se que reagir, segue-se todo impulso. Em muitos casos, esse 'ter que' já é enfermidade, declínio, sintoma de esgotamento - quase tudo o que a crueza não filosófica designa como 'vício' é apenas essa incapacidade fisiológica de não reagir" (GD/CI, O que falta aos alemães, 6, KSA 6.109, tradução de PCS). É a esta capacidade de trabalhar as próprias paixões, sem negar nenhuma delas, mas, ao contrário, usando-se delas para uma meta própria, trabalho este a ser desempenhado pela própria luta das paixões entre si; é a esta capacidade de educar suas paixões, fortalecer aquelas que se quer ver vencer as que atrapalham seus objetivos, caminho este desenvolvido pelo próprio querer das paixões, isto é, pelo jogo de mando e obediência; é o fazer com que a paixão que se quer ver forte seja realmente fortalecida a ponto de vencer 
as demais; é ao cultivo das vontades como um jardineiro; é a este processo que chamamos de liberdade.

É no livre jogo das vontades entre si que surgem as vontades mestras. Contudo, é preciso ser alguém de vontades fortes para que a mais forte seja capaz de fazer um grande trabalho. A vontade organiza a multiplicidade sem exterminá-la e usa, como vimos, até mesmo seus cães selvagens e monstros esplêndidos a seu favor, mas sem sucumbir, apenas dominando e orquestrando o caos. É preciso ter uma multiplicidade caótica de vontades fortes, mas este é apenas o solo inicial da grandeza. Seu desenvolvimento culmina com o estabelecimento de uma forte hierarquia a partir da vontade mais forte. "Hierarquia das faculdades; distância; a arte de separar sem incompatibilizar; nada misturar, nada 'conciliar'; uma imensa multiplicidade que, no entanto, é o contrário do caos" (EH/EH, Porque sou tão inteligente, 9, KSA 6.294) ${ }^{16}$. O tornar-se quem se é, é o trabalho de uma vontade em busca de sua máxima espiritualização. Mas, é um trabalho da vontade e não da razão. E, mesmo assim, a espiritualização da vontade ainda é entendida por Nietzsche como algo antinatural e precisa ser trabalhada. "É em sua natureza selvagem que o indivíduo se refaz melhor de sua desnatureza, de sua espiritualidade..." (GD/ CI, Máximas e flechas, 6, KSA 6.60, tradução de PCS).

$\mathrm{O}$ fim da crença em fórmulas morais lança a todos no labirinto existencial no qual é preciso tecer seu próprio fio de Ariadne. O conhecimento, agora, só pode ser conhecimento da vida. Não há mais receitas. Dentro deste contexto, a busca por conhecimento terá que ser feita a partir de experiências, experimentações. Criticando os religiosos pregadores da moral, Nietzsche diz: "Mas nós, os sequiosos de razão, queremos examinar nossas vivências do modo rigoroso como se faz uma experiência científica, hora a hora e dia a dia! Queremos ser nossos experimentos e nossas cobaias". (FW/GC, 319, KSA

16 NIETZSCHE, F. Ecce homo: como alguém se torna o que é. São Paulo: Companhia das letras, 1995. Tradução de Paulo César de Souza. 
Camargo, G. A.

$3.551)^{17}$ Vivenciar a própria vontade se tornou um caminho aberto, o filósofo terá neste solo sua fonte inesgotável de possibilidades e rumos. $\mathrm{O}$ caminho para a liberdade do espírito e para o conhecimento é um caminho de experiências, pois quando se decide viver por sua própria vontade, a partir de um impulso de autodeterminação, sem a moral, não se pode saber de antemão o caminho a ser tomado. $\mathrm{O}$ próprio caminho se torna uma construção a qual se chama vida. A vida liberta da moral é a única que permite o verdadeiro engrandecimento do espírito, pois este engrandecimento é, necessariamente, uma consequência do aprimoramento e aprimoramento de uma grande paixão e de uma grande vontade. Este movimento é a liberdade. A sabedoria se torna a capacidade de escolher as experiências que lhe são necessárias e conseguir crescer com elas. Caminho perigoso e desconhecido, onde se corre sempre o risco de se viver algo de insuportável e sucumbir. "Independência é algo para bem poucos:é prerrogativa dos fortes. (...) Ele penetra num labirinto, multiplica mil vezes os perigos que o viver já traz consigo; dos quais um dos maiores é que ninguém pode ver como e onde se extravia, se isola e é despedaçado por algum Minotauro da consciência" (JGB/BM, 29, KSA 5.47, tradução de PCS).

Eis a tarefa fundamental do espírito livre: "O que diz a sua consciência? - "Torne-se aquilo que você é" (FW/GC, 270, KSA 3.519, tradução de PCS). Contudo, justamente por seguir a si mesmo e por não se saber o que se é, este talvez seja o mais perigoso dos caminhos. "Para um homem que pensa o gênero de coisas que devo pensar, o perigo de se destruir é sempre iminente" (Nachlass/FP, 1885-1886, 1[1], KSA 12.9). A insegurança e a solidão serão seus companheiros, mas assim se engrandece a vida. "Pois, creiam-me! o segredo para colher da vida a maior fecundidade e a maior fruição é: viver perigosamente!" (FW/GC, 283, KSA 3.526, tradução de

17 NIETZSCHE, F. Gaia ciência. São Paulo, Companhia das letras, 2001. Tradução de Paulo César de Souza. A partir de agora indicado como PCS.

142 | Cad. Nietzsche, Guarulhos/Porto Seguro, v.42, n.3, p. 115-146, setembro/dezembro, 2021. 
PCS). Se a vida é vontade de potência, o enobrecimento se dá pelo aumento de potência, contudo, trata-se de um caos de potência a ser dominado e orquestrado; é preciso viver a potência da vontade para tornar-se aquilo que se é, e esta experiência, além de não ser segura, é imprevisível. "Acreditamos que um homem deve ter vivido de maneira absolutamente 'não filosófica', segundo os critérios tradicionais, e sobretudo não em tímida virtude - para poder julgar os grandes problemas a partir de suas experiências" (Nachlass/FP, 1885, 35[24], KSA 11.519). Se a maneira filosófica por excelência era o ascetismo, as experiências constituem uma espécie de ideal contrário, não-filosófico. A independência frente à moral abre espaço para a vontade. A vontade já foi apresentada como uma interpretação mais qualificada do que a moral para a realidade, isto porque a natureza é amoral, a vontade de potência é amoral, a vida é amoral. Assim, Nietzsche chama a moral de antinatureza e diz que "faremos bem em estudar nosso organismo em sua perfeita imoralidade" (Nachlass/ FP, 1887-1888, 11[83], KSA 13.40). Este estudo, que nos aparece como o estudo da vontade de potência, mostra não só que "as funções animais são com efeito dez milhões de vezes mais importantes do que todos os bons estados e cumes da consciência" (Nachlass/ FP, 1887-1888, 11[83], KSA 13.40), pois são mais importantes no processo de "intensificação da vida", mas mostra também que este mesmo processo de intensificação da vida, este direcionamento sempre por mais potência não só é uma característica natural da vida, como é plenamente amoral. A moral é uma invenção humana que, a partir de juízos criados historicamente, se propõe a julgar a vida. Contudo, não há como culpabilizar a vida por ela ser o que é. "É preciso estender então completamente os dedos e tentar alcançar a apreensão dessa finesse admirável, que consiste no fato de o valor da vida não poder ser avaliado" (GD/CI, O problema de Sócrates, 2 , KSA 6.68, tradução de PCS). Não é possível a uma vontade não se expressar em toda sua potência a cada instante, o que a moral tenta 
Camargo, G. A.

fazer é, justamente, esta separação entre a vontade e aquilo que ela pode, a vontade passa a negar a si mesma a partir de estados morais da consciência. "O indivíduo é, de cima a baixo, uma parcela de fatum [fado, destino], uma lei a mais, uma necessidade mais para tudo o que virá e será" (GD/CI, Moral como antinatureza, 6, KSA 6.87, tradução de PCS). Se vida é vontade de potência, se o valor da vida não pode ser apreendido pelo vivente e se os desejos e paixões são formas de expressão da vontade de potência, então, não há como moralizar a vida sem destituí-la de sua potência própria. Ao contrário, é preciso "ousar ser tão imoral quanto a natureza" (Nachlass/FP, 1887, 10[53], KSA 12.482).

\section{Freedom and will to power on Nietzsche's philosophy}

Abstract: In the present paper we propose to think about the issue of freedom in Nietzsche's philosophy. We want to know if is it possible to talk about freedom in Nietzsche's thinking, once he has made a radical critique of free will and moral? For this proposal, we will start from the characterization of the will to power, understood as an immediate expression of strength and always towards growth, and then think about it in relation to human actions, understanding that they obey the same logic. Finally, the issue of freedom will be understood as a proposal to strengthen and enhance yourself based on your strongest will and not of any moral value or social rule.

Keywords: Nietzsche, freedom, will to power.

144 | Cad. Nietzsche, Guarulhos/Porto Seguro, v.42, n.3, p. 115-146, setembro/dezembro, 2021. 
Liberdade e vontade de potência na filosofia de Nietzsche

\section{Referências}

KLOSSOWSKI, Pierre. Nietzsche e o círculo vicioso. Rio de Janeiro: Pazulin Editora, 2000. Tradução de Hortência S. Lencastre.

MARTON, Scarlett. Nietzsche: das forças cósmicas aos valores humanos. $2^{\mathrm{a}}$ edição, Belo Horizonte: Editora UFMG, 2000.

MÜLER-LAUTER, W. A doutrina da vontade de poder em Nietzsche. São Paulo: Editora Annablume, 2 2 . Ed., 1997. Tradução brasileira Oswaldo Giacóia Jr.

NIETZSCHE, F. W. Sämtliche Werke. Kritische Studienausgabe (KSA), 15 vols. (Organizada por Giorgio Colli e Mazzino Montinari), Berlim: Walter de Gruyter \& Co., 1988.

. Além do bem e do mal. Tradução de Paulo César de Souza. São Paulo: Companhia das letras, 1992.5

. Assim falou Zaratustra. Tradução de Mário da Silva. Rio de Janeiro: Civilização brasileira, 2003. 4

. Aurora. Tradução de Paulo César de Souza. São Paulo, Companhia das letras, 2004. 3

. Crepúsculo dos ídolos. Tradução de Paulo César de Souza. São Paulo: Companhia das letras, 2006. 6

. Ecce homo: como alguém se torna o que é. Tradução de Paulo César de Souza. São Paulo: Companhia das letras, 1995. 6

. Gaia ciência. Tradução de Paulo César de Souza. São Paulo, Companhia das letras, 2001. 3

. Fragments posthumes. Automne 1884-automne 1885. Oeuvres philosophiques complètes, XI. Textes et variantes établis para Giorgio Colli et Mazzino Montinari. Traduits de l'allemand par Michel Haar et Marc B. de Launay. Paris: Galimard, 1982. 11

. Fragments posthumes. Automne 1885 - automne 1887. Oeuvres philosophiques complètes, XII. Textes et variantes établis para Giorgio Colli et Mazzino Montinari. Traduits de l'allemand par Julien Hervier. Paris: Galimard, 1978. 12 
Camargo, G. A.

. Fragments posthumes. Automne 1887 - mars 1888. Oeuvres philosophiques complètes, XIII. Textes et variantes établis para Giorgio Colli et Mazzino Montinari. Traduits de l'allemand par Pierre Klossowski. Paris: Galimard, 1976. 13

. Fragments posthumes. Début 1888 - début janvier 1889. Oeuvres philosophiques complètes, XVI. Textes et variantes établis para Giorgio Colli et Mazzino Montinari. Traduits de l'allemand par Jean-Claude Hémery. Paris: Galimard, 1977. 14

WOTLING, P. Nietzsche et le problème de la civilization. Paris: PUF, 2a. ed., 1999.

Enviado: 31/03/2021

Aceito: 23/04/2021

146 | Cad. Nietzsche, Guarulhos/Porto Seguro, v.42, n.3, p. 115-146, setembro/dezembro, 2021. 